\title{
CCLXXV. ON THE ACTION OF PARATHORMONE.
}

\author{
BY HECTOR KENNETH GOADBY AND \\ REGINALD STEPHEN STACEY. \\ From the Medical Unit Laboratories, St Thomas's Hospital, London.
}

(Received September 5th, 1934.)

IT was noticed by Collip [1925] in his first experiments with parathormone on dogs, that there was a latent period after the administration of the extract before the blood-calcium started to rise. This interval has been filled in to some extent by the discovery of Albright, Ropes, Bauer and Aub [1929] who used repeated injections of parathormone in normal men; preceding the rise in serum-calcium they found an outpouring of phosphorus in the urine, followed by a fall in the plasma-inorganic phosphate. Similar results were obtained by Albright and Ellsworth [1929] in a case of idiopathic hypoparathyroidism, and the suggestion was made that the primary effect of the injection is an increased phosphate excretion, and that the rise in blood-calcium is a secondary event. Ellsworth [1932] has reported the administration of single injections of parathormone in a case of post-operative hypoparathyroidism with similar results: he suggested that the increased excretion of phosphate is produced by a "lowering of the renal threshold for phosphate," although there is no definite evidence that there is such a threshold.

The present work was directed to investigating the immediate action of parathormone on the calcium and phosphorus metabolism in man and if possible to determining the site of action of the hormone.

\section{Methods.}

The experiments to be described were done on five human subjects: two were normal healthy individuals, two were cases of post-operative tetany and one of idiopathic tetany.

After a very light breakfast no food was taken until the experiments were complete: a preliminary period of 4-5 hours was left to allow the subject to become as stable as possible; during this time and throughout the experiment $250 \mathrm{ml}$. of water were drunk each hour to ensure an adequate volume of urine for hourly or half-hourly estimations. After the preliminary period blood was drawn from an arm vein and an intramuscular injection of parathormone given. Further samples of blood were taken at intervals up to the end of the experiment. Parathormone Lilly was used, the dose being 60 units in some experiments, 100 units in others. Controls were done in which the experimental method was identical with the above but no parathormone was given.

The following estimations were carried out:

1. Phosphorus in urine. In some of the experiments this was done by the colorimetric method of Fiske and Subbarow [1925] and represents the inorganic phosphate. In others Plimmer's [1933] modification of Neumann's volumetric method was used giving the total urinary phosphorus. Similar results were obtained by the two methods. 
2. Plasma-inorganic phosphate. The blood was drawn into a $10 \mathrm{ml}$. centrifuge-tube containing two drops of $20 \%$ potassium oxalate solution, and the plasma separated at once. The method of Fiske and Subbarow was used for the estimation.

3. Calcium in urine. $100 \mathrm{ml}$. of urine were evaporated to dryness in a silica basin, ashed with nitric acid and the residue dissolved in hydrochloric acid and transferred to a $250 \mathrm{ml}$. flask; the estimation was completed volumetrically by McCrudden's [1911] method.

4. Serum-calcium. This was estimated by Clark and Collip's [1925] modification of the KramerTisdall technique.

5. Filtrable calcium in serum. Filtration was carried out at a pressure of $180 \mathrm{~mm}$. $\mathrm{Hg}$ through membranes made by the method of Northrop and Kunitz [1926] from a $7 \%$ solution of B.D.H. membrane collodion dissolved in a mixture of 40 volumes of absolute alcohol and 60 volumes of ether, $5 \mathrm{ml}$. of glycol being added to each $100 \mathrm{ml}$. of the solution. The preparation of the membranes was carefully standardised both with respect to their thickness and to the rate of drying. The same volume of serum was used for filtration in each case to avoid errors due to concentration of the non-filtrable portion, and precautions were taken to prevent evaporation during the filtration. The first $2 \mathrm{ml}$. of filtrate collected were used for determination of the calcium by the method of Clark and Collip [1925].

6. The reaction of the urine was determined by means of a B.D.H. capillator. This method is accurate to $0 \cdot 1 p_{\mathrm{H}}$ unit.

7. Urinary chloride was estimated by Harvey's [1910] technique.

\section{Results.}

Representative experiments are shown in the accompanying figures: the following descriptions are equally applicable to all the experiments performed with a single exception. This was in the case of post-operative tetany who had been treated for the preceding 9 months with daily injections of parathormone. In this experiment none of the observations made gave any indication of a reaction to 60 units of parathormone up to 5 hours after the injection, the hourly excretion of calcium and phosphorus in the urine and the plasmainorganic phosphate and serum-calcium remaining unchanged throughout. This result agrees with the findings of Aub [1928] that with repeated dosage a tolerance to parathormone is established. The other two cases of tetany had previously received only occasional doses of parathormone.

1. Urinary phosphorus. Starting immediately after the injection there was a rapid rise in the hourly phosphate excretion which reached its maximum in from $\frac{1}{2}$ to 3 hours. The most marked effect was obtained in the cases of tetany (Fig. 3), in which the hourly excretion reached a value 6 times that in the preliminary period. In the normals the increase was from 2 to 4 times (Fig. 1).

2. Plasma-inorganic phosphate. In most experiments there was a slight drop, but in no case was there a rise during the height of the phosphate excretion of more than $0.2 \mathrm{mg} . / 100 \mathrm{ml}$.

3. Urinary calcium. During the hour following the injection this either remained constant or showed a tendency to rise. Later there was a definite fall.

4. Serum-calcium. There was little change in the serum-calcium up to 5 hours after the injection, but in some experiments there was a slight rise towards the end of this period. The filtrable calcium also showed no significant change and followed a course parallel with the total calcium.

5. Volume of urine. A definite diuresis after parathormone, as has been described by Hueper [1929] and by Taylor [1926], was observed in some of the experiments. The hourly phosphate excretion however was independent of the volume of urine passed.

6. Urinary $\mathrm{p}_{H}$. There was little change in this during the course of the experiments. 

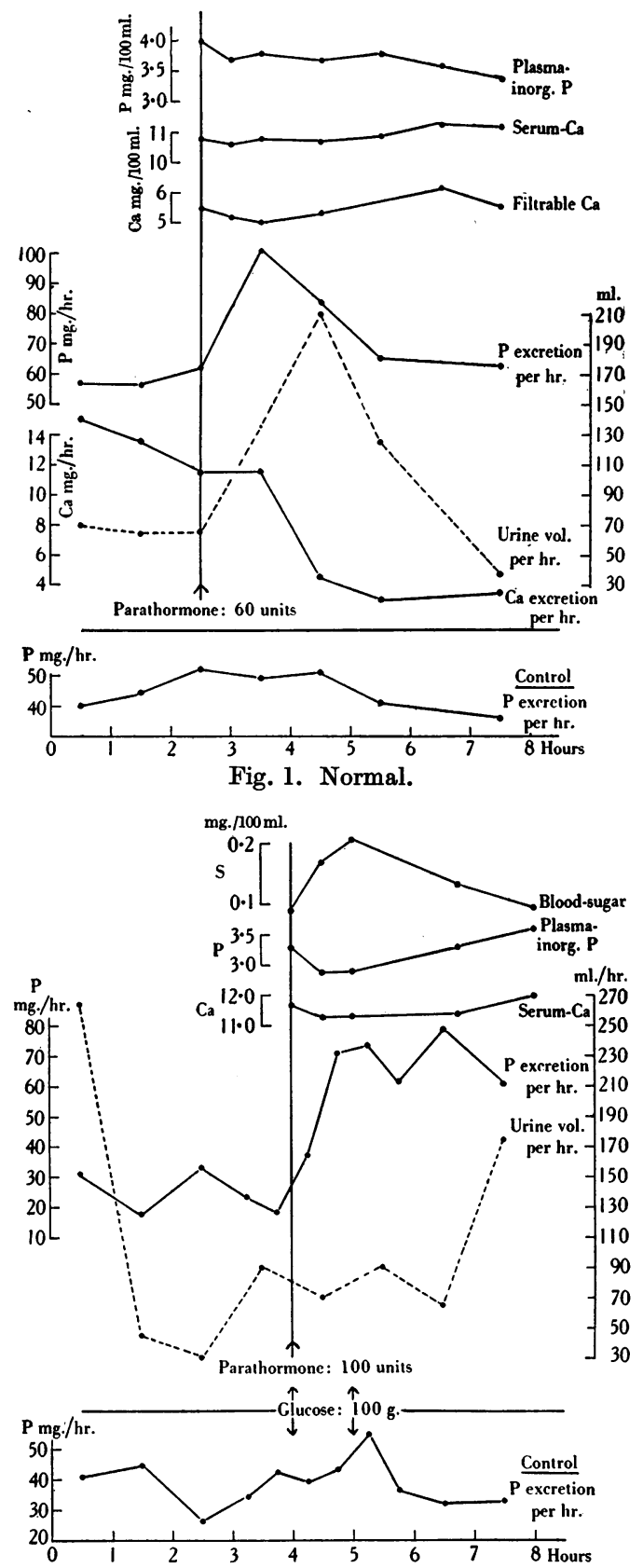

Fig. 2. Normal.

7. Urinary chloride. The hourly output of chloride varied enormously, and there was no evidence that parathormone affected the chloride excretion in any of the experiments.

From the results detailed above it is evident that following parathormone 
injection there is a sudden large rise in the urinary phosphate excretion: this does not reflect a rise in the inorganic phosphate in the plasma as the latter may even be falling. To show more conclusively the dissociation of urinary and bloodphosphorus changes, two experiments were performed in which a drop in the

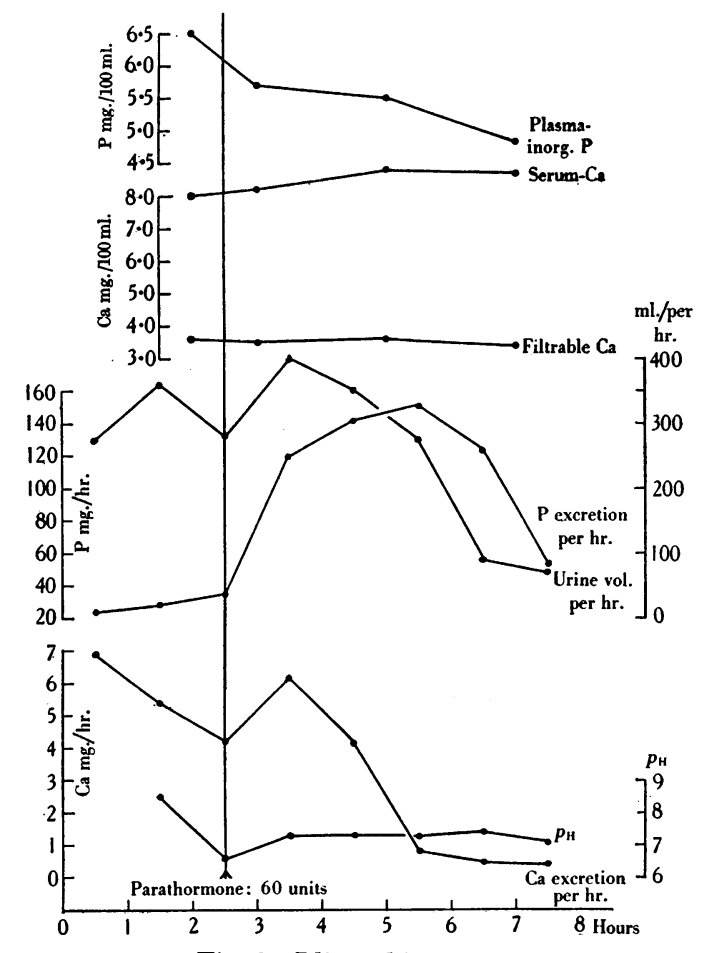

Fig. 3. Idiopathic tetany.

plasma-inorganic phosphate was obtained by giving $100 \mathrm{~g}$. of glucose by mouth at the time of the parathormone injection, and a further $100 \mathrm{~g} .1$ hour later. The results are given in Fig. 2. In spite of the fall in the plasma-inorganic phosphate, there was a considerable rise in the urinary phosphate output.

\section{Discussion.}

The immediate origin of the extra phosphorus excreted in the urine under the action of parathormone can conceivably be either the blood or the kidney substance. The latter possibility can be disposed of at once. Taking the approximate phosphorus content of the kidney to be $0 \cdot 19 \mathrm{~g}$. per $100 \mathrm{~g}$. tissue (the highest figure given by Cullen et al. [1933]), the total phosphorus in the two kidneys would be about $0.6 \mathrm{~g}$. The total extra phosphorus excreted in one of the above experiments was $0.82 \mathrm{~g}$. It is inconceivable that the kidney could be completely depleted of phosphorus, so that the assumption is that the extra phosphorus comes from the inorganic or the organic phosphorus of the blood.

Some further insight into the mechanism of the action of parathormone may be obtained by considering these two fractions of the blood-phosphorus separately as possible sources of the extra phosphorus excreted. According to Pincus et al. [1926] the inorganic phosphate in the plasma is completely filtrable through the 
kidney: it has been shown above that a parathormone phosphate diuresis occurs even with a falling blood-inorganic phosphate: if this fraction supplies the extra phosphorus then parathormone must in some way facilitate the excretion of phosphate by increasing the power of the kidney to concentrate it.

It has been shown by Kay [1928] that the kidney is second only to intestinal mucous membrane in its phosphatase content: it is possible that parathormone may promote the breakdown of organic phosphate in the blood by the kidneyphosphatase. In one experiment a series of determinations of the acid-soluble phosphate of the plasma was carried out: no change was found during the course of the experiment, although the usual large extra excretion of phosphate occurred.

From our experiments the point of action of parathormone must be limited to three possibilities, namely the kidney inorganic phosphate excretion mechanism, the kidney-phosphatase, or the organic phosphorus reserves in the blood or tissues. Further work is proceeding to investigate these possibilities.

\title{
SUMMARY.
}

1. The first apparent action of parathormone is to increase the rate of excretion of phosphorus in the urine.

2. This occurs in normal persons, and was also true in two out of the three cases of hypoparathyroidism investigated.

3. The increased excretion of phosphorus is independent of the concentration of inorganic phosphorus in the blood-plasma.

We wish to express our gratitude to Prof. O. L. V. S. de Wesselow for permission to use his cases and for much criticism and advice.

This work was undertaken during tenure of a grant from the Medical Research Council by one of us (R.S.S.).

\section{REFERENCES.}

\author{
Albright, Bauer, Ropes and Aub (1929). J. Clin. Invest. 7, 139. \\ - and Ellsworth (1929). J. Clin. Invest. 7, 183. \\ Aub (1928). The Harvey Lectures, Harvey Soc. of New York, 24, 151. \\ Clark and Collip (1925). J. Biol. Chem. 63, 461. \\ Collip (1925). J. Biol. Chem. 63, 395. \\ Cullen, Wilkins and Harrison (1933). J. Biol. Chem. 102, 415. \\ Ellsworth (1932). J. Clin. Invest. 11, 211. \\ Fiske and Subbarow (1925). J. Biol. Chem. 66, 375. \\ Harvey (1910). Arch. Int. Med. 6, 12. \\ Hueper (1929). Arch. Int. Med. 44, 374. \\ Kay (1928). Biochem. J. 22, 855. \\ MacLean (1919). Biochem. J. 13, 135. \\ McCrudden (1911). J. Biol. Chem. 10, 187. \\ Northrop and Kunitz (1926). J. Gen. Physiol. 9, 351. \\ Pincus, Peterson and Kramer (1926). J. Biol. Chem. 68, 601. \\ Plimmer (1933). Biochem. J. 27, 1810. \\ Taylor (1926). Amer. J. Physiol. 74, 221.
}

Note added September 5th, 1934. On going to press we find a short notice of investigations by Ellsworth and Howard (Proc. of Amer. Soc. Clin. Invest., J. Clin. Invest. (1934), 13, 705) who have found similar results to those described in this paper. 